\title{
The Influence of Socio-Demographic Characteristics on Patient Satisfaction in Family Medicine Clinics of Karachi
}

\author{
Sannia Perwaiz Iqbal ${ }^{1 *}$ and Waris Qidwai

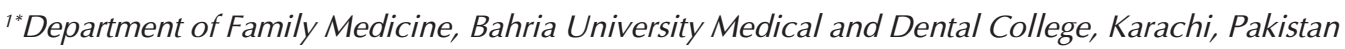 \\ ${ }^{2}$ Department of Family Medicine, The Aga Khan University Hospital, Karachi, Pakistan
}

\begin{abstract}
Background: In the field of family medicine, patient satisfaction holds the utmost value. Patient satisfaction surveys help family physicians; understand their patients' needs, learn about patients' experiences, identify areas of dissatisfaction, improve their practice and increase job satisfaction.

Objective: To determine the association of patients' satisfaction with demographic and socio-economic characteristics of patients visiting the family medicine clinics of the Aga Khan University.

Methods: This cross-sectional study was conducted at family medicine clinics at the Integrated Medical Service Centers, Aga Khan University, Karachi, from January 2017 to July 2017. A total of 160 consecutive patients (48 males and 112 females, age range 18 - 65 years) visiting the family medicine clinics were recruited with informed consent. A validated questionnaire consisting of 18 items was administered to all patients who consented to participate in the study. The reasons for dissatisfaction were also assessed. Descriptive statistics were calculated. Stratification was done, and the association of satisfaction with age, gender, marital status, education, and economic status was investigated using the chi-square test. The $p$-value $\leq 0.05$ was considered significant.
\end{abstract}

Results: Out of a total of 160 study participants, $86.3 \%$ indicated their satisfaction, while $13.8 \%$ were found to be dissatisfied with the services at the family medicine clinic. The most common reason $(50 \%)$ for dissatisfaction among the dissatisfied patients was the state of OPD facilities. On chi-square analysis, gender $(p=0.028)$, education level $(p=0.010)$ and socioeconomic status $(p=0.002)$ were found to be significantly different among satisfied and dissatisfied patients. On multivariable analysis, education, marital status and socioeconomic status were found to be independently associated with patient satisfaction.

Conclusion: The results showed that higher satisfaction was associated with higher education, higher socioeconomic status and higher among the widowed population.

Keywords: Patient satisfaction, family medicine, outpatient department, socio-demographic characteristics, education.

\section{INTRODUCTION}

Patient satisfaction is an important indicator of healthcare outcomes and can be an effective tool in assessing healthcare service quality. Patient satisfaction can most easily be defined as the patient's view of the healthcare services received and the extent to which patients' expectations were met [1]. Patient satisfaction surveys are the primary source of patient feedback and provide valuable information about the patients' overall healthcare experience. They are crucial in identifying deficiencies and carrying out necessary reforms. Healthcare organizations have employed patient satisfaction surveys extensively as analysis of this information allows them to modify processes, structures, and outcomes in patient care. Patient satisfaction helps build patient loyalty and is directly linked to the continuity of care, reduced risk of litigations, increased patient compliance and improved healthcare outcomes [2].

*Corresponding author: Sannia Perwaiz Iqbal, Department of Family Medicine, Bahria University Medical and Dental College, Karachi, Pakistan; Email: sanniapi@gmail.com

Received: April 06, 2021; Revised: May 31, 2021; Accepted: June 03, 2021 DOI: https://doi.org/10.37184//lnjpc.2707-3521.3.6
In Pakistan, a competitive marketplace has emerged in healthcare today, and patients' satisfaction has become even more critical. With most healthcare services being delivered by the private sector, medical organizations are striving to provide better quality services to attain greater patient satisfaction.

A comparative study conducted on patient satisfaction in private and public sector hospitals in Pakistan concluded that patients from private sector hospitals are more satisfied than those in public sector hospitals. It is interesting to note that both groups were found to be equally unsatisfied about the time spent with doctors [3]. In the field of family medicine, patient satisfaction holds the utmost value. A family physician is a trained medical expert able to provide comprehensive, continuous, and patient-centered care to individuals and their families irrespective of their age, gender, or illness. They are expected to be responsive and respectful of their patients' needs, preferences, and values [4]. Patient satisfaction is a top priority for family physicians. Patient satisfaction surveys help family physicians; understand their patients' needs, learn about patients' experiences, identify areas of dissatisfaction, improve their practice and increase job satisfaction. It also demonstrates that a 
family physician is interested in feedback from patients and quality care [5].

A study done on patients' expectations from family physicians in Karachi found that the highest-ranked patients' expectations were "an adequate explanation of their diagnosis and treatment". Some other expectations that followed included maintaining privacy and confidentiality, reduced costs, decreased waiting time for the appointment, and increased consultation time with the doctor [6]. Family physicians must meet these expectations to have satisfied patients.

A study carried out in eight primary healthcare clinics of Karachi reported $95 \%$ overall patient satisfaction. In that study, family physician's communication skills had the greatest impact on patient satisfaction. Respondents reported high levels of satisfaction regarding respect and courtesy, personal interest, reassurance and time offered to the patients by the family physicians [7]. Another multi-center study conducted at 18 family medicine clinics of Karachi found that most patients were very satisfied with their family physician (the mean patient satisfaction score was $82.8 \%$ ). Areas of dissatisfaction included long waiting times before the appointment and inaccessibility of doctors on the phone [8].

A focus on patients' satisfaction can lead to improvement in the professional skills of the physicians as well as aid in the delivery of better treatment and healthcare. Incorporation of patients' satisfaction research findings at the national level can help improve patients' satisfaction with the healthcare system in Pakistan and will also lead to improvement of healthcare in the country. Such lines of evidence can be of great value to have policy dialogue with government officials to incorporate this information in the public sector hospitals and healthcare institutions in order to have a positive impact on public health. Our study's objective was to assess patient satisfaction with family medicine services in the integrated medical services centers of a major tertiary care hospital in Karachi, where patients are seen by family physicians at a highly subsidized rate and also to determine the influence of various socio-demographic characteristics on patient satisfaction.

\section{METHODS}

Our study was a cross-sectional survey conducted at the family medicine clinics of the integrated medical services centers of the Aga Khan University Hospital, Karachi from January 10, 2017 to July 9, 2017. Non-probability consecutive sampling technique was employed for the study.

Ethical approval was obtained from the Ethics Review Committee of the Aga Khan University before the study's commencement. Written informed consent was taken from the patients after explaining to them the purpose of the study and the protocol involved. Standard measures were taken to ensure the confidentiality of the participants. Patients were approached in the clinics after their consultation with the family physician. The sample size was calculated through WHO software for sample size determination. It is calculated based on the proportion of patients satisfied with health care and the reasons for their dissatisfaction.

From the previous studies, we found that $90 \%$ was the highest prevalence of patients satisfied with the family medicine clinics [9]. Therefore, with a 5\% margin of error at a $95 \%$ confidence level the sample size was calculated to be 140 . After inflating the sample size $(10 \%)$ for non-responders the final sample size came out to be approximately 160 participants.

Both male and female patients between the ages of 18 and 65 who consented to participate in the survey were included in the study. Patients with mental illness and communication problems were excluded from the study. The questionnaire was composed of three sections. Section one included the demographic details of patients such as age, gender, marital status, education level, and socioeconomic status.

Socioeconomic status (SES) was categorized according to monthly income into low, middle and high SES. Patients with a monthly income of $<20,000$ Pakistani rupees (PKR) were categorized as having low socioeconomic status. Patients with a monthly income between 20,000 to 50,000 PKR were categorized as having middle socioeconomic status and patients having a monthly income of more than $>50,000$ PKR were categorized as having higher SES.

Section two included the Patient's Satisfaction Questionnaire (PSQ) [10], a validated questionnaire to assess patients' satisfaction. The Patient Satisfaction Questionnaire was developed by Ware et al. [11], who proposed seven dimensions of patient satisfaction. These include general satisfaction with medical care, satisfaction with technical quality, interpersonal manner, communication, financial aspects, time spent with the doctor, and accessibility and convenience. The short-form instrument, the PSQ-18 was utilized for our study which contains 18 questions tapping each of the seven dimensions of satisfaction with medical care. A score of $10 / 18(60 \%)$ questions if answered in agreement reflected satisfaction while a score lower than 10 was labelled as dissatisfaction.

Section three included additional structured questions to identify reasons for dissatisfaction. The reasons for dissatisfaction were assessed using binary response questions. The contents of these questions were based on findings from earlier studies. [6, 8, 9]. 
These included three broad categories: dissatisfaction with the physician, dissatisfaction with the staff, and dissatisfaction with the OPD facilities. Dissatisfaction with the physicians asked questions regarding the physician's behavior towards the patient, clinical competence, explanation of the diagnosis and treatment, and the consultation time. Dissatisfaction with staff included questions regarding staff's behavior, maintenance of patient's privacy, and the staff's technical abilities. Dissatisfaction with the OPD facilities included the center's overall cleanliness, financial cost, waiting time, and accessibility through the phone.

Data were entered and analyzed in SPSS@ version 21 (IBM, USA). Baseline information on demographics was analyzed using descriptive statistics. Continuous variables such as age, mean and standard deviation were calculated. For categorical variables such as gender, education level and socioeconomic status, frequencies and percentages were reported.

Post-stratification, Fisher's exact test was applied to study the relationship of patient satisfaction with gender, age, marital status, education, and socioeconomic status of patients. Logistic regression analyses were performed to determine the change in odds of patient satisfaction after adjusting for confounding variables. A p-value of less than 0.05 was considered statistically significant.

\section{RESULTS}

A total of 160 patients were evaluated to measure the frequency of patients' satisfaction and identify primary reasons for patients' dissatisfaction about their visit. Out of 160 study subjects, 48(30\%) were males and 112 $(70 \%)$ were females. The overall mean age of study subjects was $43.03 \pm 12.98$ years.

In our study, $86.3 \%$ of patients (138 of 160) were satisfied with family medicine services, while only $22(13.7 \%)$ of patients dissatisfied. Reasons of dissatisfaction are presented in Fig. (1). Table 1 shows comparison of participants' characteristics among satisfied and dissatisfied patients. Age $(p=0.790)$ and marital status $(p=0.214)$ were not significantly different among the two groups. Gender $(p=0.028)$, education level $(p=0.010)$ and socioeconomic status $(p=0.002)$ were significantly different among the two groups.

Table 2 is representing univariate and multivariable analysis to ascertain the association of patients' demographics with their satisfaction. On multivariable model, education level was found to be associated with patients' satisfaction with significantly higher odds of being satisfied among individuals' with secondary education $(\mathrm{aOR}=11.33$ 95\% Cl: 2.03-63.29) and post-graduate higher education (aOR=11.83, 95\% Cl: 2.22-63.12) as compared to illiterate patients. Marital status was also identified as an independent predictor of patients' education with a higher likelihood of satisfaction among widowed patients than single people $(\mathrm{aOR}=42,95 \% \mathrm{Cl}$ : 1.28-1374.7). The socioeconomic status of patients was also found to be associated with patients' satisfaction. The odds of satisfaction were significantly lower in people belonging to middle SES than higher SES $(\mathrm{aOR}=0.09$, 95\% Cl: 0.02-0.37).

Table 1: Comparison of participants' characteristics among satisfied and dissatisfied patients.

\begin{tabular}{|c|c|c|c|c|}
\hline \multirow[t]{2}{*}{ Variable } & \multirow[t]{2}{*}{ Groups } & \multicolumn{2}{|c|}{ Patient Satisfaction } & \multirow[t]{2}{*}{ p-value } \\
\hline & & No $(n=22)$ & Yes $(n=138)$ & \\
\hline Age (in years) [mean $\pm \mathrm{SD}$ ] & - & $42.2 \pm 15.8$ & $43.2 \pm 12.6$ & 0.790 \\
\hline Gender [n (\%)] & Female & $11(9.8)$ & $101(90.2)$ & *0.028 \\
\hline \multirow{3}{*}{ Education [n (\%)] } & None & $7(30.4)$ & $16(69.6)$ & \multirow{3}{*}{$\neq^{*} 0.011$} \\
\hline & Intermediate & $6(23.1)$ & $20(76.9)$ & \\
\hline & Higher & $3(5.1)$ & $56(94.9)$ & \\
\hline \multirow{3}{*}{ Marital Status [n (\%)] } & Never married & $5(22.7)$ & $17(77.3)$ & \multirow{3}{*}{$\#^{*} 0.214$} \\
\hline & Currently married & $14(13.9)$ & $87(86.1)$ & \\
\hline & Divorced & $2(22.2)$ & $7(77.8)$ & \\
\hline
\end{tabular}

F Fisher-exact test is reported

* Statistically significant at $p<0.05$ 
Table 2: Logistic regression models studying the association of socio-demographic characteristics with Patient satisfaction.

\begin{tabular}{|c|c|c|c|c|c|}
\hline Characteristics & Group & Crude OR & $95 \% \mathrm{Cl}$ & Adjusted OR & $95 \% \mathrm{Cl}$ \\
\hline Age & - & 1.01 & $(0.97-1.04)$ & 0.95 & $(0.89-1.01)$ \\
\hline Gender & Female & Ref & & Ref & \\
\hline \multirow{3}{*}{ Education } & Not educated & Ref & & Ref & \\
\hline & Primary & 1.90 & $(0.41-8.82)$ & 5.28 & $(0.76-36.68)$ \\
\hline & Higher & 8.17 & $(1.89-35.42)^{*}$ & 11.83 & $(2.22-63.12)^{*}$ \\
\hline \multirow{4}{*}{ Marital Status } & Never married & Ref & & Ref & \\
\hline & Currently married & 1.83 & $(0.58-5.75)$ & 4.85 & $(0.70-33.66)$ \\
\hline & Divorced & 1.03 & $(0.16-6.62)$ & 4.90 & $(0.26-91.18)$ \\
\hline & Widowed & 6.76 & $(0.72-63.33)$ & 42.00 & $(1.28-1374.7)^{\star}$ \\
\hline
\end{tabular}

$\mathrm{Cl}=$ confidence interval, $\mathrm{OR}=$ odds ratio, Ref= reference category, ${ }^{*} \mathrm{p}$-value $<0.05$

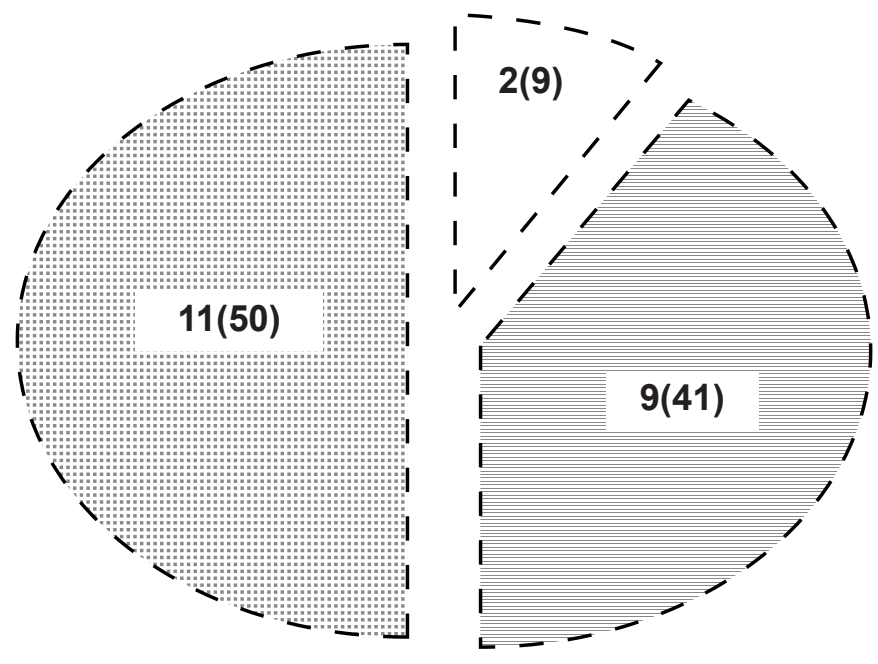

Dissatisfication with physician

Dissatisfication with behaviour of staff Dissatisfication with OPD facilities

Fig. (1): Reasons for dissatisfaction of patients visiting the family medicine clinic $(n=22)$.

\section{DISCUSSION}

The overall patient satisfaction with the family medicine services reported in our study was $86.3 \%$. Similar studies carried out in Pakistan on patient satisfaction with family medicine services also reported high patient satisfaction levels [7, 8]. Globally, family physicians have demonstrated high patient satisfaction scores. A study conducted in Saudi Arabia to evaluate patient satisfaction with different aspects of the family medicine healthcare services showed a high rate $(90 \%)$ of overall patient satisfaction [9], while a study from the UK reported $82 \%$ [12]. In comparison, a Canadian study reported $88 \%$ overall patient satisfaction with family physicians [13]. A Turkish study reported $88 \%$ [14] and in comparison, an Iranian study reported $76 \%$ of the respondents to be satisfied with the family medicine services' care [15]. Effective communication and timeliness of care were factors contributing the most to overall patient satisfaction in these studies.

Our study results showed that most of the patients seeking health at the clinic were female $(70 \%)$ and a greater percentage of female patients $(73.2 \%)$ were 
satisfied compared to male patients. $(P=0.03)$. These findings agree with similar studies $[16,17]$ in which the female gender was associated with higher patient satisfaction. Opposing results have been reported in other satisfaction studies showing male patients to be more satisfied as compared to female patients [18, 19]. Therefore, gender could be considered an inconsistent predictor of patient satisfaction, which is also backed up by other studies $[20,21]$.

On logistic regression analysis, age was not found to be associated with patient satisfaction. These findings are in agreement with a meta-analysis conducted by Hall et al. [21], who also reported no influence of age on patient satisfaction.

The literature also appears to have mixed results about the influence of age on patient satisfaction. Several studies reported higher patient satisfaction associated with younger patients [22, 23] and others reporting older patients to be more satisfied [24]. In our study, we found that higher education level was associated with higher patient satisfaction $(P=0.01)$. These findings are in line with those reported by Afzal et al. [16]. Still, they are different from the results of other satisfaction studies carried out in Pakistan where higher education had been reported to be associated with decreased patients' satisfaction [19].

A possible reason for these opposing results could be that the other satisfaction studies were conducted at public sector hospitals, while our study was carried out in a private sector hospital. The higher educated population is aware of the level of care in private and public hospitals. They expect high-quality healthcare and effective communication regarding their care. Consequently, these higher expectations may lead to dissatisfaction of the more educated population in public sector hospitals. Moreover, many international studies have also reported high satisfaction with higher education levels, since higher educated individuals are more involved in their care, more likely to comply with their treatment, and have improved health care outcomes [25-27].

We also found that patients with a higher socioeconomic status were more satisfied with the family medicine services $(P=0.001)$. These findings agree with other studies [28] who also reported individuals of higher socioeconomic status to be more satisfied. Although opposing results were reported by Jawaid et al. [29], who reported lower socioeconomic status associated with higher patient satisfaction. These opposing findings could be attributed to the difference in a health care setting (public vs. private).
In our study, there was a significant association found between marital status and patient satisfaction with the widowed patients showing higher patient satisfaction. These findings are corroborated by the results of Afzal et al. [16] but different from Chen et al. [25], who did not report any significant association of marital status with patient satisfaction.

In our study, $13.8 \%$ of the patients were found to be dissatisfied. It was observed that out of the $13.8 \%, 50 \%$ of the patients were dissatisfied with the OPD facilities, $40.9 \%$ were dissatisfied with the staff and $9.1 \%$ of the patients were dissatisfied with the physician.

Similar to our study, dissatisfaction with OPD facilities has been the major reason for dissatisfaction in other satisfaction surveys conducted in Pakistan and India $[30,31]$.

Our results showed that the widowed patients, patients having higher socioeconomic status and higher education were found to have higher patient satisfaction. Generally, in Pakistan, people who have higher education also have a higher socioeconomic status. They are more likely to gain satisfaction from the consultation skills of trained family physicians. As compared to patients belonging to the socioeconomic class, who also have hidden agendas like medicine and free tests, their perception as to what constitutes a good consultation may be different. The consultation skills of family physicians may be more appealing to people of higher social class.

As for widows, our presumption that widows in the Pakistani society are hardly given due importance so we presume that good communication skills of family physicians which include active listening is probably a novel experience for the widowed population who are getting heard after a long time.

\section{CONCLUSION}

Our study concluded that patient satisfaction was higher among the widowed population and also associated with higher education and higher socioeconomic status. Patient satisfaction is a top priority for all doctors including family physicians all over the world. A focus on patient satisfaction can lead to improved clinical practices by family physicians and aid in delivering better treatment results. Family physicians working anywhere in Pakistan must assess patient satisfaction in order to ensure patient's confidence in the quality of healthcare.

\section{STRENGTHS OF THE STUDY}

Our study is unique from other patient satisfaction studies with family medicine services carried out in the 
country as we used a validated questionnaire for our study and also explored the association of various socio-demographic variables on patient satisfaction and the reasons for patients' dissatisfaction.

\section{STUDY LIMITATIONS}

The small sample size of this study limits its applicability. The main limitations of the present study include a single-center experience and a nonrandomized study design. It was conducted in an urban setting and therefore, the results may not be generalisable to larger populations. A multi-centre study using a large sample size would be needed to further confirm these findings. A large sample size would enable the application of logistic regression while adjusting for covariates to confirm the association of various variables with patients' satisfaction.

\section{ETHICS APPROVAL}

Ethical approval was obtained from the Ethics Review Committee of the Aga Khan University. All procedures performed in studies involving human participants were following the ethical standards of the Helsinki declaration.

\section{CONSENT FOR PUBLICATION}

Written informed consent was taken from the patients after explaining to them the purpose of the study and the protocol involved.

\section{FUNDING}

Our study involved no funding.

\section{CONFLICTS OF INTEREST}

The authors declare no conflict of interest.

\section{ACKNOWLEDGEMENTS}

We would like to thank all the study participants and the healthcare personnel for their support and assistance.

\section{REFERENCES}

1. Al-Abri R, Al-Balushi A. Patient satisfaction survey as a tool towards quality improvement. Oman Med J 2014; 29(1): 3-7.

2. Prakash B. Patient satisfaction. J Cutan Aesthet Surg 2010; 3(3): 151-5.

3. Khattak A, Alvi MI, Yousaf MA, Shah SZA, Turail D, Akhter S. Patient satisfaction-a comparison between public \& private hospitals of Peshawar. Int J Collab Res Intern Med Public Health 2012; 4(5): 713-22.
4. Martin JC, Avant RF, Bowman MA, Bucholtz JR, Dickinson JR, Evans $\mathrm{KL}$, et al. The future of family medicine: a collaborative project of the family medicine community. Ann Fam Med 2004; 2 Suppl 1: S3-S32.

5. White B. Measuring patient satisfaction: how to do it and why to bother. Fam Pract Manag 1999; 6(1): 40-44.

6. Qidwai W, Dhanani RH, Khan FM. Implications for the practice of a patient expectation and satisfaction survey at a teaching hospital in Karachi, Pakistan. J Pak Med Assoc 2003; 53(3): 122-5.

7. Siddiqui S, Amin F, Saboor F. Factors Associated with patient satisfaction - evidence from a primary care not for profit organization In Karachi. J Bahria Univ Med Dent Coll 2019; 9(1): $38-42$.

8. Ali NS, Khuwaja AK, Kausar S, Nanji K. Patients' evaluations of family practice care and attributes of a good family physician. Qual Prim Care 2012; 20(5): 375-83.

9. Al-Faris EA, Khoja TA, Falouda M, Saeed AA. Patients' satisfaction with accessibility and services offered in Riyadh health centers. Saudi Med J 1996; 17(1): 11-7.

10. Marshall GN, Hays RD. The patient satisfaction questionnaire short-form (PSQ 18). Available at: https://www.rand.org/ content/dam/rand/pubs/papers/2006/P7865.pdf

11. Ware JE Jr, Snyder MK, Wright WR, Davies AR. Defining and measuring patient satisfaction with medical care. Eval Program Plann 1983; 6(3-4): 247-63

12. Grol R, Wensing M, Mainz J, Jung HP, Ferreira $P$, Hearnshaw $H$, et al. Patients in Europe evaluate general practice care: an international comparison. Br J Gen Pract 2000; 50(460): 882-7.

13. Wetmore S, Boisvert L, Graham E, Hall S, Hartley T, Wright L, et al. Patient satisfaction with access and continuity of care in a multidisciplinary academic family medicine clinic. Can Fam Phys 2014; 60(4): e230-e236.

14. Aktürk Z, Ateşoğlu D, Çiftçi E. Patient satisfaction with family practice in Turkey: Three-year trend from 2010 to 2012. Eur J Gen Pract 2015; 21(4): 238-45.

15. Taheri M, Mohammadi M, Amani A, Zahiri R, Mohammadbeigi A. Family physician program in Iran, patients satisfaction in a multicenter study. Pak J Biol Sci 2014; 17: 227-33.

16. Afzal M, Khan A, Rizvi F, Hussain A. Patients satisfaction levels in out patient department of a teaching hospital. J Islamabad Med Dent Coll 2012; 1(1): 26-9.

17. Ahmad I, Nawaz A, ud Din S. Dynamics of patient satisfaction from health cares services. Gomal J Med Sci 2010; 9: 37-41.

18. Al-Eisa IS, Al-Mutar MS, Radwan MM, Al-Terkit AM. Patients' satisfaction with primary health care services at capital health region, Kuwait. Middle East J Fam Med 2005; 3: 277-300.

19. Naseer M, Zahidie A, Shaikh BT. Determinants of patient's satisfaction with healthcare system in Pakistan: a critical review. Pak J Public Health 2012; 2(2): 56-61.

20. Thiedke CC. What do we really know about patient satisfaction? Fam Pract Manag 2007; 14: 33-6.

21. Hall JA, Dornan MC. Patient socio-demographic characteristics as predictors of satisfaction with medical care: a meta-analysis. Soc Sci Med 1990; 30(7): 811-8 
22. DeVoe JE, Wallace LS, Fryer GE Jr. Patient age influences perceptions about health care communication. Fam Med 2009; 41: 126-33.

23. Ibrahim A. Patient satisfaction with health services at the outpatient department of Indira Gandi Memorial Hospital, Male' Maldives. J Public Health Develop 2008; 6(1): 144-52.

24. Jaipaul CK, Rosenthal GE. Are older patients more satisfied with hospital care than younger patients? Gen Intern Med 2003; 18 : 23-30.

25. Chen H, Li M, Wang J, Xue C, Ding T, Nong X, et al. Factors influencing inpatients' satisfaction with hospitalization service in public hospitals in Shanghai, People's Republic of China. Patient Prefer Adher 2016; 10: 469-77.

26. Bu-Alayyan S, Mostafa A, El-Etaibi B, Sorkhou E, Al- Taher H, Al-Weqayyan A. Patient satisfaction with primary health care services in Kuwait. Kuwait Med J 2008; 40(1): 25-30.

27. Owaidh AO, Atiah AA, Abadi AS. Patients' satisfaction with health care services in Southern Saudi Arabia. Egypt J Hosp Med 2018; 72(1): 3857-60.
28. Baltaci D, Eroz R, Ankarali H, Erdem O, Celer A, Korkut $\mathrm{Y}$. Association between patients' socio-demographic characteristics and their satisfaction with primary health care services in Turkey. Kuwait Med J 2013; 45: 291-9.

29. Jawaid A, Ahmed N, Alam SN, Rizvi B, Razzak HA. Patient's experiences and satisfaction from surgical outpatient department of a tertiary care teaching hospital. Pak J Med Sci 2009; 25(3): 439-42.

30. Khan NA, Aslam SK, Rehman AU, Qureshi MS, Inam S, Samo KA et al. Satisfaction level and its predictors among out patients at public sector hospital in Karachi. J Dow Uni Health Sci 2014; 8(3): $104-10$

31. Kumari R, Idris M, Bhushan V, Khanna A, Agarwal M, Singh S. Study on patient satisfaction in the government allopathic health facilities of Lucknow District, India. Indian J Community Med 2009; 34(1): 35-42. 